\title{
DNMT3A co-mutation in an IDH1-mutant glioblastoma
}

\author{
Elena I. Fomchenko, ${ }^{1}$ E. Zeynep Erson-Omay, ${ }^{1}$ Amy Zhao, ${ }^{1}$ Ranjit S. Bindra, ${ }^{2}$ \\ Anita Huttner, ${ }^{3}$ Robert K. Fulbright, ${ }^{4}$ and Jennifer Moliterno ${ }^{1}$ \\ ${ }^{1}$ Department of Neurosurgery, ${ }^{2}$ Department of Therapeutic Radiology, ${ }^{3}$ Department of Pathology, \\ ${ }^{4}$ Department of Radiology, Yale School of Medicine, New Haven, Connecticut 06520, USA
}

\begin{abstract}
Glioblastomas are highly aggressive, infiltrative, and genetically heterogeneous primary brain tumors that arise de novo or secondarily progress over time from low-grade tumors. Along with well-established signature mutational profiles, emerging research suggests that the epigenetic tumor landscape plays an important role in gliomagenesis via transcriptional regulation, DNA methylation, and histone modifications. The pursuit of targeted therapeutic approaches, based not only on expression profiles but also on somatic mutations, is fundamental to the effort of improving survival in patients with glioblastoma. Here, we describe a missense DNMT3A p.P904S mutation in an IDH1-mutant glioblastoma. Although never previously reported in gliomas, this mutation is predicted to be pathogenic and has been reported in several other malignancies. Our report suggests that elucidating epigenetic control is important to understanding glioblastoma biology and may likely unveil targets potentially important to glioblastoma treatment in an effort to improve survival.
\end{abstract}

[Supplemental material is available for this article.]

\section{INTRODUCTION}

Glioblastoma multiforme (GBM) is a WHO Grade IV glioma, comprising more than one-half of primary brain tumors (Louis et al. 2016); these tumors are known for their highly aggressive and infiltrative nature as well as their genetic heterogeneity (Verhaak et al. 2010; Brennan et al. 2013). GBMs arise de novo or progress from low-grade gliomas (i.e., secondary GBMs), with corresponding molecular signatures, and can be further classified based on their molecular expression or genomic alteration profiles (Verhaak et al. 2010; Brennan et al. 2013; Sun et al. 2014). For instance, IDH1 mutations and 1p19q loss are associated with oligodendroglial histology, whereas ATRX mutations correlate with astrocytic tumors (Cancer Genome Atlas Research Network et al. 2015; Louis et al. 2016). Primary GBMs are associated with loss of PTEN and CDKN2A and with EGFR amplifications, whereas secondary GBMs frequently carry IDH1 R132H mutations (Wong et al. 1992; Yan et al. 2009; Brennan et al. 2013; Ohgaki and Kleihues 2013; Bai et al. 2016).

Based on such expression profiles, along with clinical characteristics, patients with GBMs fall into four different subtypes: proneural, atypical, proliferative, and mesenchymal, with the proneural subgroup seemingly associated with better survival (Verhaak et al. 2010; Brennan et al. 2013; Sun et al. 2014). Despite the current standard of care treatment, including aggressive surgical resection and adjuvant radiation therapy (RT) combined with the alkylating agent temozolomide (TMZ), the prognosis for patients diagnosed with GBM remains poor, with an overall median survival of $\sim 14 \mathrm{mo}$ after initial diagnosis, and $<10 \%$ of patients survive $>5$ yr (Lacroix et al. 2001; Stupp et al. 2005, 2015; Sanai et al. 2011; Chinot et al. 2014). 
The pursuit of more targeted therapeutic approaches has become fundamental in an effort to prolong survival in patients with GBM. Whole-exome sequencing provides invaluable promise to guiding multidisciplinary treatments. Herein, we describe a patient with an IDH1-, ATRX-, and TP53-mutant GBM, who also harbored a somatic mutation in the DNA methyltransferase 3 alpha (DNMT3A) gene, all of which were preserved during progression and recurrence. DNMT3A gene alterations relate to aberrant DNA methylation and associated tumorigenesis in other malignancies. The somatic mutation found, p.P904S, has previously been reported in other cancers, but never in GBM, and has been predicted to be pathogenic (Forbes et al. 2017). The patient, who has been treated with multiple aggressive surgical resections and standard of care and novel therapies, remains alive nearly $3 \mathrm{yr}$ after his initial diagnosis of GBM.

\section{RESULTS}

\section{Clinical Presentation}

The patient is an otherwise healthy 39-yr-old male who initially presented in 2016 with progressively worsening headaches and clumsiness. Magnetic resonance imaging (MRI) of the brain showed a large heterogeneously enhancing right fronto-parietal mass with associated vasogenic edema and infiltrative tumor (Fig. 1A,D). He underwent subtotal resection (STR) at an outside hospital followed by standard 60-Gy fractionated conformal RT and concomitant TMZ (Stupp et al. 2005). Pathology was consistent with an IDH1 R132H-mutant, MGMTmethylated GBM with a Ki67 of 10\%-15\%. The patient was referred to our institution

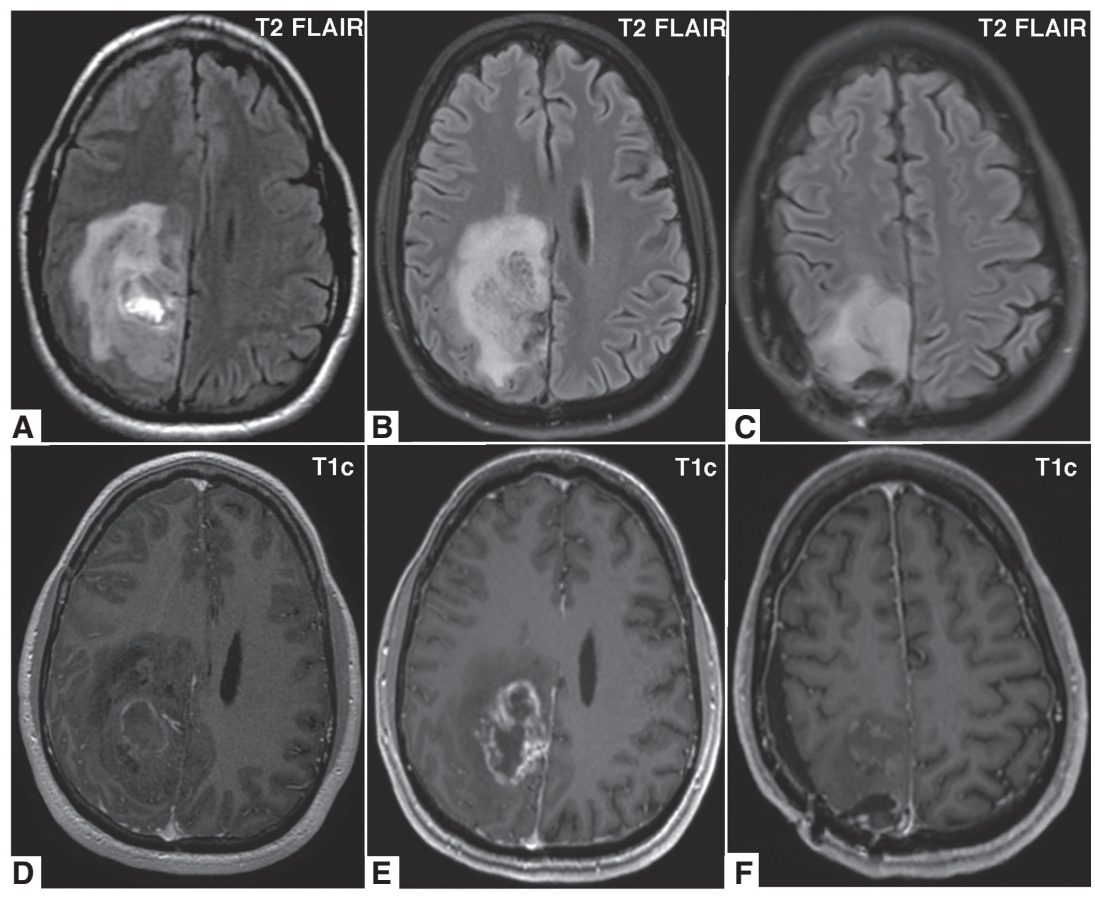

Figure 1. Magnetic resonance imaging (MRI) of a patient with DNMT3a co-mutation in an IDH1-mutant recurrent glioblastoma. $(A, D)$ Preoperative imaging for the initial lesion operated on at the outside hospital 3/2016; $(B, E)$ the first recurrence of the GBM 8 mo later; $(C, F)$ the second recurrence of the GBM 23 mo thereafter. Axial T2-weighted FLAIR $(A-C)$ and axial T1-weighted $(D-F)$ with gadolinium contrast images are shown. 
COLD SPRING HARBOR Molecular Case Studies
DNMT3A co-mutation in an IDH1-mutant glioblastoma
3 months after his initial surgery, when he was started on the PARP inhibitor, veliparib (ABT-888), along with adjuvant TMZ (Alliance trial A071102; NCT02152982).

The brain MRI after four cycles of veliparib/TMZ and $8 \mathrm{mo}$ after his original presentation was concerning for relapse (Fig. 1B,E). Concurrently, the patient began exhibiting weakness and left agraphesthesia. He underwent repeat STR, with a small amount of residual tumor left along the motor strip. The pathology was consistent with the initial surgery. Postoperatively, he underwent treatment with INC280, a highly potent selective cMet inhibitor, and the VEGFR/PDGFR inhibitor, bevacizumab, and remained neurologically and radiographically stable through 22 cycles of treatment. However, a brain MRI showed disease progression again 30 mo after initial diagnosis. An fMRI was obtained and showed the anterolateral displacement of the motor tracts and tumor proximity to the lower extremity somatosensory region. The patient underwent his third STR, 23 mo after his second surgery, with expected anterior inferior residual disease (Fig. 1C,F). Pathology again returned as IDH1-mutant, MGMT-methylated, GFAP-positive GBM without EGFR or cMet amplifications. Ki67 was elevated at $10 \%-15 \%$. The patient then was started on off-label nivolumab and underwent $35-G y$ reirradiation to the tumor bed.

His overall survival to date is 32 mo after the initial diagnosis of GBM, with progressionfree survival of $8 \mathrm{mo}$ after initial resection, postoperative RT with concurrent TMZ, and veliparib/TMZ on the Alliance trial, and $22 \mathrm{mo}$ after repeat resection/INC280/bevacizumab followed by reirradiation with nivolumab.

\section{Genomic Analyses}

Whole-exome sequencing of the first recurrence, which had been treated with 60-Gy RT and TMZ, identified 37 somatic mutations in the captured protein coding regions (Fig. 2A; Supplemental Table 1), including IDH1 p.R132H, TP53 p.C176F, and ATRXp.Q2108R mutations. Curiously, a missense DNMT3A p.P904S mutation affecting a highly conserved catalytic methyltransferase domain responsible for DNA/cofactor binding was identified in this tumor (Table 1). The DNMT3A p.P904S mutation was previously reported in AML, DLBCL, and esophageal squamous cell carcinoma, and mutations in DNMT3A residue 904 also have been reported in 25 cases in multiple other malignancies (Sawada et al. 2016; Forbes et al. 2017; Thol et al. 2017; Wong et al. 2018). Of note, no DNMT3A mutations affecting residue 904 were reported in gliomas in COSMIC. Analysis of the TCGA database identified eight DNMT3A mutations in six TCGA-GBM patients and 10 DNMT3A mutations in 10 TCGA-LGG patients in residues other than 904; two TCGA-GBM patients carried two DNMT3A mutations each, similar to AML patients (Grossman et al. 2016). Of note, four of eight mutations in TCGA-GBM patients and five of 10 mutations in TCGA-LGG patients localized to the DNMT3A methyltransferase domain, suggestive of their functional relevance; three of 10 mutations in TCGA-LGG patients were premature STOP codons resulting in truncated dysfunctional protein, including one localized to methyltransferase domain. Prevalence of DNMT3A mutations in 3106 CNS malignancies and in 2421 gliomas reported in COSMIC, all in residues other than P904, was 26, including 18 missense, three nonsense, and one frameshift; 10 of these localized to the methyltransferase domain (Forbes et al. 2017). No $\mathrm{LOH}$ events, or large-scale chromosomal aberrations, were noted in this recurrent tumor.

The second recurrent specimen, after multiple cycles of chemotherapy and targeted therapy treatment, was more heterogeneous, with 104 somatic mutations in the captured protein coding regions (Fig. 2A,B; Supplemental Table 2). Only 19 mutations found in the first recurrent GBM were preserved in the second recurrent tumor. Of these, only four mutations, IDH1 p.R132H, TP53 p.C176F, ATRX p.Q2146R, and DNMT3A p.P904S, are reported to be drivers in various cancer types. Interestingly, DNMT3A p.P904S, which was not reported in GBMs before, had high variant allele frequency in the second recurrent tumor, 


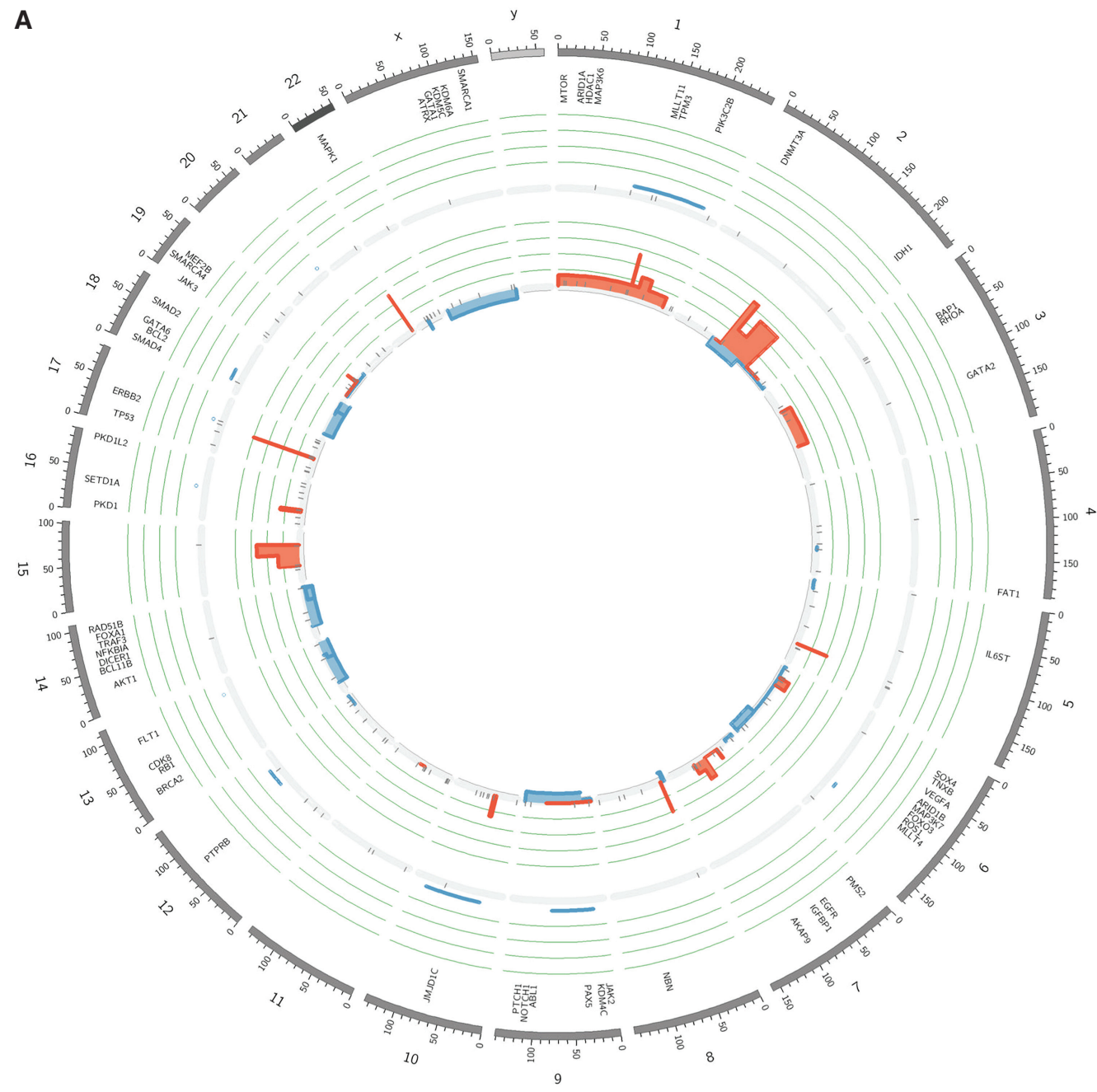

B

\begin{tabular}{cccccccc}
\hline Type & Gene & Chr & Pos & Ref & Alt & Coding variant & AA change \\
\hline M & DNMT3A & 2 & 25457177 & G & A & c.C2710T & p.P9045 \\
\hline M & IDH1 & 2 & 209113112 & C & T & c.G395A & p.R132H \\
\hline M & TP53 & 17 & 7578403 & C & A & c.G527T & p.C176F \\
\hline M & ATRX & X & 76814207 & T & C & c.A6323G & p.Q2108R \\
\hline FS & ATRX & X & 76849257 & TAACA & T & c.5901_5904del & p.F1967fs \\
\hline M & PRAMEF11 & 1 & 12887174 & C & T & & p.R228H \\
\hline FS & PMS2 & 7 & 6017239 & AG & A & c.2424delC & p.A808fs \\
\hline M & FAT1 & 4 & $1.88 E+08$ & T & C & c.A12139G & p.T4047A \\
\hline SPL & AKAP9 & 7 & 91669987 & G & T & c.4693-1G>T &. \\
\hline M & HLSST & 5 & 55247363 & A & G & c.T1586C & p.V529A \\
\hline M & PTPRB & 12 & 70928667 & C & A & c.G5226T & p.M17421 \\
\hline SPL & NBN & 8 & 90967505 & A & C & c.1397+6T>G &. \\
\hline
\end{tabular}

Figure 2. CIRCOS plot representing the genomic profile of patient's first recurrent and second recurrent glioblastoma, including somatic mutations and copy-number variations. The outermost circle represents the first recurrent glioblastoma; the innermost circle represents the second recurrent glioblastoma. Dark gray hash marks represent individual somatic mutations; selected mutations are labeled on the graph. Dark red and blue bars represent copy-number variations, gains and losses, respectively. (B) Summary table annotating somatic mutations detected in patient's second recurrent glioblastoma, previously associated with cancer; mutations with VAF > 9\% are included. M stands for missense mutations; STOP stands for STOP gained. 


\begin{tabular}{|c|c|c|c|c|c|c|c|}
\hline Gene & Chromosome & $\begin{array}{l}\text { HGVS DNA } \\
\text { reference }\end{array}$ & $\begin{array}{l}\text { HGVS protein } \\
\text { reference }\end{array}$ & $\begin{array}{l}\text { Variant } \\
\text { type }\end{array}$ & $\begin{array}{l}\text { Predicted effect } \\
\text { (substitution, } \\
\text { deletion, etc.) }\end{array}$ & $\begin{array}{l}\text { dbSNP/ } \\
\text { dbVar ID }\end{array}$ & $\begin{array}{c}\text { Genotype } \\
\text { (heterozygous/ } \\
\text { homozygous) }\end{array}$ \\
\hline DNMT3A & 2 & c.C2710T & p.P904S & Missense & TDPDDDDMDD & & Heterozygous \\
\hline
\end{tabular}

suggesting that it is in the founder clone preserved during tumor progression. In addition to the ATRX p.Q2108R mutation in the first recurrent tumor, a second frameshift mutation was identified in ATRX p.F1967fs. In comparison to the first recurrence, the second recurrent tumor harbored multiple LOH events, including Chromosome 13 region containing RB1. In addition, second recurrent GBM acquired a variety of large-scale chromosomal events, including gains in Chromosome 1, Chromosome 3, Chromosome 6p, Chromosome 7, Chromosome 17, and Chromosome 19p and losses of Chromosome 6, Chromosome 9, Chromosome 13, Chromosome 14, Chromosome 18, and Chromosome X (Fig. 2A; Supplemental Tables 3,4). Chromosome $2 \mathrm{CNVs}$ and $\mathrm{LOH}$ events were noted as well, none involving chromosomal regions containing DNMT3A (Supplemental Tables 3 and 4). There was no $1 p 19 q$ codeletion in either the first or second recurrent specimen. $C N V$ analysis has been repeated using publicly available tools yielding similar results.

\section{DISCUSSION}

The 130-kDa protein product of DNMT3A, a member of the DNA methyltransferase family, is responsible for de novo DNA methylation of cytosine residues within $\mathrm{CpG}$ sites independent of DNA replication (Ley et al. 2010; Russler-Germain et al. 2014). DNMT3A contains the regulatory domain comprised of the Pro-Trp-Trp-Pro (PWWP) domain involved in DNA/histone binding, the ATRX-DNMT3-DNMT3L (ADD) domain responsible for $\mathrm{H} 3$ histone tail interactions, and the adenosyl methionine (SAM)-dependent catalytic methyltransferase C5-type domain responsible for methyl group transfer to five position of cytosine. During normal development, DNMT3A has been shown to play a role in early embryogenesis, imprinting, and spermatogenesis via its interactions with DNMT3L, which regulates its oligomerization and methyltransferase activity (Jia et al. 2007; Holz-Schietinger and Reich 2010). Mutations in any of these domains have been shown to be tumorigenic and particularly associated with $\mathrm{AML}$, as well as other hematologic malignancies (Okano et al. 1999; Brunetti et al. 2017). We describe a patient with an IDH1-mutant recurrent glioblastoma, carrying a somatic mutation in DNMT3A p.P904S localizing to the highly conserved catalytic domain, never previously reported in glioblastoma patients. Although most DNMT3A mutations affect R882 residue within the catalytic domain, resulting in $80 \%$ reduction in DNMT3A enzymatic activity and dominant negative effects on the wild-type DNMT3A by blocking the formation of active tetramers, other somatic mutations including frameshift, splice site, missense, and nonsense mutations at non-R882 residues result in expression of nonfunctional or truncated protein and a haploinsufficient phenotype (Ley et al. 2010; Yamashita et al. 2010; Yan et al. 2011; Hájková et al. 2012; Russler-Germain et al. 2014). Studies suggest significantly diminished de novo methyltransferase activity with focal hypomethylation in R882-mutant AML and support worse overall survival and higher recurrences in AML patients carrying DNMT3A mutations (Hájková et al. 2012). Moreover, expression profiling of patient-derived primary AML samples have shown decreased DNMT3A activity with up-regulation of HOX genes that play a role in hematopoiesis and AML oncogenesis (Yan et al. 2011). 
COLD SPRING HARBOR Molecular Case Studies
DNMT3A co-mutation in an IDH1-mutant glioblastoma
In the recent years, the epigenetic tumor landscape has been shown to play an increasingly important role in the tumor biology via transcriptional regulation, because of the changes in methylation of $\mathrm{CpG}$ islands within gene promoter regions, and histone modifications, with resulting changes in chromatin structure and accessibility to transcriptional activators or repressors. The association between altered DNA methylation and gliomagenesis has been well-described (Pajtler et al. 2015; Sturm et al. 2016; Capper et al. 2018). Although IDH1-mutant gliomas, similar to AML, show global genome hypomethylation proposed to be associated with genomic instability, CpG islands within promoters of tumor-suppressor genes are frequently methylated, resulting in their inactivation of transcription (Cancer Genome Atlas Research Network et al. 2013; Bai et al. 2016). DNMT3A can affect chromatin modifications via its interactions with histone modifiers including EZH2, SUV39H1, SETDB1, and EHMT2 (Epsztein-Litman et al. 2008; Karimi et al. 2011; Yang et al. 2013). Conditional DNMT3A deletion in hematopoietic stem cells results in a marked increase in self-renewal in lieu of differentiation, possibly via its effects on Ctnnb1 with its concomitant promoter hypomethylation, $\beta$-catenin overexpression, and up-regulation of target gene expression (Challen et al. 2014); DNMT3A has likewise been implicated in neural stem cell differentiation (Wu et al. 2012). Existence of DNMT3A mutations in TCGA-LGG (low-grade glioma) and TCGA-GBM patients, $50 \%$ of which affect methyltransferase domain containing DNMT3A P904S mutation, supports the notion that it likely is a premalignant driver event. Indeed, DNMT3A mutations are present in founder AML clones, have been shown to be important in AML oncogenesis, and often confer resistance to conventional chemotherapy. Multiple DNMT3A mutations can cooccur in the same AML patient, similarly seen in the TCGAGBM patient cohort carrying DNMT3A mutations (Thol et al. 2017; Wong et al. 2018). It is possible that DNMT3A mutations are premalignant events that skew neural stem/progenitor cells toward self-renewal rather than differentiation, possibly via epigenetic mechanisms, contributing to glioma initiation.

In this case, we describe a patient harboring a GBM with somatic co-mutations in IDH1, TP53, and ATRX, as well as DNMT3A. IDH1- or IDH2-mutant gliomas have been well-studied and associated with nearly twice the median overall survival as nonmutated counterparts (Cairncross et al. 2013, 2014; van den Bent et al. 2013; Ostrom et al. 2015). The IDH1 p. R132H mutation, in particular, has molecularly been well-described and clinically shown to carry a better prognostic significance for GBM patients. IDH1-mutant GBMs, as compared to IDH1 wild-type GBMs, demonstrate hypermethylation of CpG islands, with the mechanism of action thought to be competitive inhibition of a-ketoglutarate-dependent dioxygenases, including TET2 and JMJ C hydroxylases by D2HG, which disrupts normal patterns of DNA and histone methylation in a process similar to AML (Noushmehr et al. 2010; Lu et al. 2012; Turcan et al. 2012). More recently, the biological importance of DNA methylation profiles in CNS tumors, characterizing various GBM subtypes, has been demonstrated (Capper et al. 2018). According to TCGA, up to $44 \%$ of AML patients carry mechanistically and prognostically important mutations in genes regulating genome methylation, including frequent mutations in DNMT3A in as much as 30\% normal karyotype AML patients, Tet oncogene family member 2 deoxygenase (TET2), and isocitrate dehydrogenases 1/2 (IDH1/2) (Figueroa et al. 2010; Yan et al. 2011; Cancer Genome Atlas Research Network et al. 2013; Thol et al. 2017). In AML patients, DNMT3A somatic mutations are commonly present together with mutations in IDH1/2, FLT3, NPM1, and cKit and are mutually exclusive with mutations in TET2 (Ley et al. 2010; Im et al. 2014; Thol et al. 2017). It has been proposed that the type of DNMT3A mutation and gene dosage effects, combined with secondary mutations, may dictate the type of hematologic disease (Yang et al. 2015). Interestingly, IDH and DNMT3A mutations were shown to have mutually exclusive, opposing effects on the epigenome, with cooccurrence of both mutations resulting in epigenetic antagonism, in which CpG sites affected by either IDH or DNMT3A mutations alone are no longer affected 
COLD SPRING HARBOR Molecular Case Studies
DNMT3A co-mutation in an IDH1-mutant glioblastoma in the presence of both, with the overall loss of differential methylation within gene compartments (Glass et al. 2017). Our findings underscore the importance of better elucidating the role of epigenetic mechanisms in the initiation and progression of GBMs, with the possibility that targeting them may be helpful to improve outcomes and survival.

\section{METHODS}

This study was approved by Yale University's Human Investigations Committee and Human Research Protection Program. Informed consent was obtained from the patient prior to collection of blood and tumor samples. Pathology and imaging were evaluated by boardcertified neuropathologists per WHO classification criteria. Genomic DNA was isolated using standard phenol-chloroform techniques. Sequencing was performed at the Yale Center for Genome Analysis (YCGA) as previously described using Illumina platform. Coding sequences were captured using xGEN Exome Research Panel v1.0 (Integrated DNA Technologies); reads were aligned to GRCh37 human genome using BWA-MEM (v0.7.10) and processed with Picard to exclude PCR duplicates (v1.18). Multisequence realignment, base quality recalibration, and HaplotypeCaller were available through Genome Analysis Toolkit (GATK; v3.2-2). Somatic SNVs were identified using MuTect (v2.7.1); somatic insertion or deletions (indels) were identified using Indelocator (v36.3). Raw SNVs were filtered using "GATKBest Practice" parameters (https://software.broadinstitute.org/gatk/) and annotated with ANNOVAR (v.2015-12-14) and VEP (v.83). Somatic calls were filtered based on their presence in control databases ExAC, 1000 Genomes, and NHLBI (<1\%). Copy-number variations (CNVs) were assessed using tumor over normal coverage ratios, normalized by total coverage variation. DNAcopy in house R script was used for segmentation. Copy-number neutral loss of heterozygosity (LOH) was computed using VAF shift for germline heterozygous mutations in tumor versus blood. Tumor cell purity of $78.8 \%$ was reported for the second recurrent GBM, based on deviation of tumor VAF for $\mathrm{LOH}$ regions as compared to blood; computational prediction of the tumor cell purity is not available because of the lack of $\mathrm{LOH}$ in the initial recurrence GBM. Mean coverages of $165.5 \times / 96.5 \times$ and $266 \times / 96.5 \times$ were achieved for tumor versus blood from the initial recurrence GBM (second resection) and second recurrence GBM (third resection), respectively (Supplemental Table 5). CNV analysis has been repeated using ExomeCNV package, with the log ratio of depth of coverage for tumor and blood calculated by the Depth of Coverage tool by GATK.

\section{ADDITIONAL INFORMATION}

\section{Data Deposition and Access}

Variant described in this manuscript has been submitted to ClinVar (https://www.ncbi.nlm .nih.gov/clinvar/) (SUB5780842) under accession number SCV000924296. Raw sequencing data is available by contacting the authors.

\section{Ethics Statement}

The whole-exome sequencing performed in this study was approved by Yale University's Human Investigations Committee and Human Research Protection Program, HIC Protocol Number 9406007680. Informed consent was obtained from the patient prior to collection of blood and tumor samples. 
COLD SPRING HARBOR Molecular Case Studies
DNMT3A co-mutation in an IDH1-mutant glioblastoma
Competing Interest Statement

The authors have declared no competing interest.

Received February 13, 2019; accepted in revised form May 7, 2019.

\section{Acknowledgments}

The authors wish to acknowledge Dr. Joseph Piepmeier, the neurosurgeon, who performed the two recurrent surgeries.

\section{Author Contribution}

E.I.F. developed the manuscript, along with the assistance of A.Z., and created the clinical summary and figures and tables. E.Z.E.-O. performed and interpreted whole-exome sequencing analysis and also developed the manuscript and edited tables. A.H. performed histologic analysis of pathology specimens and grading according to WHO criteria. R.K.F. performed imaging review and interpretation and critically evaluated and edited the imaging figure. J.M. directed the study with interpretation of clinical and scientific findings and developed the manuscript. R.S.B. reviewed and edited the manuscript regarding aspects of RT and IDH1/2-mutant biology. All authors critically edited the manuscript. The authors report no pertinent disclosures, and no conflict of interest concerning the materials or methods used in this study or findings described in this paper.

\section{REFERENCES}

Bai H, Harmanci AS, Erson Omay EZ, Li J, Coskun S, Simon M, Krischek B, Özduman K, Omay SB, Sorensen EA, et al. 2016. Integrated genomic characterization of IDH1 mutant glioma malignant progression. Nat Genet 48: 59-66. doi:10.1038/ng.3457

Brennan CW, Verhaak RG, McKenna A, Campos B, Noushmehr H, Salama SR, Zheng S, Chakravarty D, Sanborn JZ, Berman SH, et al. 2013. The somatic genomic landscape of glioblastoma. Cell 155: 462477. doi:10.1016/j.cell.2013.09.034

Brunetti L, Gundry MC, Goodell MA. 2017. DNMT3A in leukemia. Cold Spring Harb Perspect Med 7: a030320. doi:10.1101/cshperspect.a030320

Cairncross G, Wang M, Shaw E, Jenkins R, Brachman D, Buckner J, Fink K, Souhami L, Laperriere N, Curran W, et al. 2013. Phase III trial of chemoradiotherapy for anaplastic oligodendroglioma: long-term results of RTOG 9402. J Clin Oncol 31: 337-343. doi:10.1200/JCO.2012.43.2674

Cairncross JG, Wang M, Jenkins RB, Shaw EG, Giannini C, Brachman DG, Buckner JC, Fink KL, Souhami L, Laperriere NJ, et al. 2014. Benefit from procarbazine, lomustine, and vincristine in oligodendroglial tumors is associated with mutation of IDH. J Clin Oncol 32: 783-790. doi:10.1200/JCO.2013.49.3726

Cancer Genome Atlas Research Network, Ley TJ, Miller C, Ding L, Raphael BJ, Mungall AJ, Robertson A, Hoadley K, Triche TJ Jr, Laird PW, et al. 2013. Genomic and epigenomic landscapes of adult de novo acute myeloid leukemia. N Engl J Med 368: 2059-2074. doi:10.1056/NEJMoa1301689

Cancer Genome Atlas Research Network, Brat DJ, Verhaak RG, Aldape KD, Yung WK, Salama SR, Cooper LA, Rheinbay E, Miller CR, Vitucci M, et al. 2015. Comprehensive, integrative genomic analysis of diffuse lowergrade gliomas. N Engl J Med 372: 2481-2498. doi:10.1056/NEJMoa1402121

Capper D, Jones DTW, Sill M, Hovestadt V, Schrimpf D, Sturm D, Koelsche C, Sahm F, Chavez L, Reuss DE, et al. 2018. DNA methylation-based classification of central nervous system tumours. Nature 555: 469474. doi:10.1038/nature26000

Challen GA, Sun D, Mayle A, Jeong M, Luo M, Rodriguez B, Mallaney C, Celik H, Yang L, Xia Z, et al. 2014. Dnmt3a and Dnmt3b have overlapping and distinct functions in hematopoietic stem cells. Cell Stem Cell 15: 350-364. doi:10.1016/j.stem.2014.06.018

Chinot OL, Wick W, Mason W, Henriksson R, Saran F, Nishikawa R, Carpentier AF, Hoang-Xuan K, Kavan P, Cernea D, et al. 2014. Bevacizumab plus radiotherapy-temozolomide for newly diagnosed glioblastoma. N Engl J Med 370: 709-722. doi:10.1056/NEJMoa1308345

Epsztein-Litman S, Feldman N, Abu-Remaileh M, Shufaro Y, Gerson A, Ueda J, Deplus R, Fuks F, Shinkai Y, Cedar $\mathrm{H}$, et al. 2008. De novo DNA methylation promoted by G9a prevents reprogramming of embryonically silenced genes. Nat Struct Mol Biol 15: 1176-1183. doi:10.1038/nsmb.1476

Figueroa ME, Abdel-Wahab O, Lu C, Ward PS, Patel J, Shih A, Li Y, Bhagwat N, Vasanthakumar A, Fernandez $H F$, et al. 2010. Leukemic IDH1 and IDH2 mutations result in a hypermethylation phenotype, disrupt TET2 function, and impair hematopoietic differentiation. Cancer Cell 18: 553-567. doi:10.1016/j.ccr.2010.11 .015 
Forbes SA, Beare D, Boutselakis H, Bamford S, Bindal N, Tate J, Cole CG, Ward S, Dawson E, Ponting L, et al. 2017. COSMIC: somatic cancer genetics at high-resolution. Nucleic Acids Res 45: D777-D783. doi:10 $.1093 / \mathrm{nar} / \mathrm{gkw} 1121$

Glass JL, Hassane D, Wouters BJ, Kunimoto H, Avellino R, Garrett-Bakelman FE, Guryanova OA, Bowman R, Redlich S, Intlekofer AM, et al. 2017. Epigenetic identity in AML depends on disruption of nonpromoter regulatory elements and is affected by antagonistic effects of mutations in epigenetic modifiers. Cancer Discov 7: 868-883. doi:10.1158/2159-8290.CD-16-1032

Grossman RL, Heath AP, Ferretti V, Varmus HE, Lowy DR, Kibbe WA, Staudt LM. 2016. Toward a shared vision for cancer genomic data. N Engl J Med 375: 1109-1112. doi:10.1056/NEJMp1607591

Hájková H, Marková J, Haškovec C, Sárová I, Fuchs O, Kostečka A, Cetkovský P, Michalová K, Schwarz J. 2012. Decreased DNA methylation in acute myeloid leukemia patients with DNMT3A mutations and prognostic implications of DNA methylation. Leuk Res 36: 1128-1133. doi:10.1016/j.leukres.2012.05.012

Holz-Schietinger C, Reich NO. 2010. The inherent processivity of the human de novo methyltransferase 3A (DNMT3A) is enhanced by DNMT3L. J Biol Chem 285: 29091-29100. doi:10.1074/jbc.M110 .142513

Im AP, Sehgal AR, Carroll MP, Smith MP, Tefferi A, Johnson DE, Boviadzis M. 2014. DNMT3A and IDH mutations in acute myeloid leukemia and other myeloid malignancies: associations with prognosis and potential treatment strategies. Leukemia 28: 1774-1783. doi:10.1038/leu.2014.124

Jia D, Jurkowska RZ, Zhang X, Jeltsch A, Cheng X. 2007. Structure of Dnmt3a bound to Dnmt3L suggests a model for de novo DNA methylation. Nature 449: 248-251. doi:10.1038/nature06146

Karimi MM, Goyal P, Maksakova IA, Bilenky M, Leung D, Tang JX, Shinkai Y, Mager DL, Jones S, Hirst M, et al. 2011. DNA methylation and SETDB1/H3K9me3 regulate predominantly distinct sets of genes, retroelements, and chimeric transcripts in mESCs. Cell Stem Cell 8: 676-687. doi:10.1016/j.stem.2011.04.004

Lacroix M, Abi-Said D, Fourney DR, Gokaslan ZL, Shi W, DeMonte F, Lang FF, McCutcheon IE, Hassenbusch SJ, Holland E, et al. 2001. A multivariate analysis of 416 patients with glioblastoma multiforme: prognosis, extent of resection, and survival. J Neurosurg 95: 190-198. doi:10.3171/jns.2001.95.2.0190

Ley TJ, Ding L, Walter MJ, McLellan MD, Lamprecht T, Larson DE, Kandoth C, Payton JE, Baty J, Welch J, et al. 2010. DNMT3A mutations in acute myeloid leukemia. N Engl J Med 363: 2424-2433. doi:10.1056/ NEJMoa1005143

Louis DN, Ohgaki H, Wiestler OD, Cavenee WK. 2016. WHO classification of tumours of the central nervous system, revised 4th ed. IARC Publications, Lyon.

Lu C, Ward PS, Kapoor GS, Rohle D, Turcan S, Abdel-Wahab O, Edwards CR, Khanin R, Figueroa ME, Melnick A, et al. 2012. IDH mutation impairs histone demethylation and results in a block to cell differentiation. Nature 483: 474-478. doi:10.1038/nature 10860

Noushmehr H, Weisenberger DJ, Diefes K, Phillips HS, Pujara K, Berman BP, Pan F, Pelloski CE, Sulman EP, Bhat KP, et al. 2010. Identification of a CpG island methylator phenotype that defines a distinct subgroup of glioma. Cancer Cell 17: 510-522. doi:10.1016/j.ccr.2010.03.017

Ohgaki H, Kleihues P. 2013. The definition of primary and secondary glioblastoma. Clin Cancer Res 19: 764 772. doi:10.1158/1078-0432.CCR-12-3002

Okano M, Bell DW, Haber DA, Li E. 1999. DNA methyltransferases Dnmt3a and Dnmt3b are essential for de novo methylation and mammalian development. Cell 99: 247-257. doi:10.1016/S0092-8674(00) 81656-6

Ostrom QT, Gittleman H, Fulop J, Liu M, Blanda R, Kromer C, Wolinsky Y, Kruchko C, Barnholtz-Sloan JS. 2015. Central Brain Tumor Registry of the United States (CBTRUS) statistical report: primary brain and central nervous system tumors diagnosed in the United States in 2008-2012. Neuro Oncol 17: 1-62. doi:10.1093/neu onc/nov189

Pajtler KW, Witt H, Sill M, Jones DT, Hovestadt V, Kratochwil F, Wani K, Tatevossian R, Punchihewa C, Johann $P$, et al. 2015. Molecular classification of ependymal tumors across all CNS compartments, histopathological grades, and age groups. Cancer Cell 27: 728-743. doi:10.1016/j.ccell.2015.04.002

Russler-Germain DA, Spencer DH, Young MA, Lamprecht TL, Miller CA, Fulton R, Meyer MR, ErdmannGilmore P, Townsend RR, Wilson RK, et al. 2014. The R882H DNMT3A mutation associated with AML dominantly inhibits wild-type DNMT3A by blocking its ability to form active tetramers. Cancer Cell 25: 442-454. doi:10.1016/j.ccr.2014.02.010

Sanai N, Polley MY, McDermott MW, Parsa AT, Berger MS. 2011. An extent of resection threshold for newly diagnosed glioblastomas. J Neurosurg 115: 3-8. doi:10.3171/2011.2.JNS10998

Sawada G, Niida A, Uchi R, Hirata H, Shimamura T, Suzuki Y, Shiraishi Y, Chiba K, Imoto S, Takahashi Y, et al. 2016. Genomic landscape of esophageal squamous cell carcinoma in a Japanese population. Gastroenterology 150: 1171-1182. doi:10.1053/j.gastro.2016.01.035

Stupp R, Mason WP, van den Bent MJ, Weller M, Fisher B, Taphoorn MJ, Belanger K, Brandes AA, Marosi C, Bogdahn U, et al. 2005. Radiotherapy plus concomitant and adjuvant temozolomide for glioblastoma. $N$ Engl J Med 352: 987-996. doi:10.1056/NEJMoa043330 
Stupp R, Taillibert S, Kanner AA, Kesari S, Steinberg DM, Toms SA, Taylor LP, Lieberman F, Silvani A, Fink KL, et al. 2015. Maintenance therapy with tumor-treating fields plus temozolomide vs temozolomide alone for glioblastoma: a randomized clinical trial. JAMA 314: 2535-2543. doi:10.1001/jama.2015.16669

Sturm D, Orr BA, Toprak UH, Hovestadt V, Jones DTW, Capper D, Sill M, Buchhalter I, Northcott PA, Leis I, et al. 2016. New brain tumor entities emerge from molecular classification of CNS-PNETs. Cell 164: 1060-1072. doi:10.1016/j.cell.2016.01.015

Sun Y, Zhang W, Chen D, Lv Y, Zheng J, Lilljebjörn H, Ran L, Bao Z, Soneson C, Sjogren HO, et al. 2014. A glioma classification scheme based on coexpression modules of EGFR and PDGFRA. Proc Natl Acad Sci 111: 3538-3543. doi:10.1073/pnas.1313814111

Thol F, Klesse S, Köhler L, Gabdoulline R, Kloos A, Liebich A, Wichmann M, Chaturvedi A, Fabisch J, Gaidzik VI, et al. 2017. Acute myeloid leukemia derived from lympho-myeloid clonal hematopoiesis. Leukemia 31: 1286-1295. doi:10.1038/leu.2016.345

Turcan S, Rohle D, Goenka A, Walsh LA, Fang F, Yilmaz E, Campos C, Fabius AW, Lu C, Ward PS, et al. 2012. IDH1 mutation is sufficient to establish the glioma hypermethylator phenotype. Nature 483: 479-483. doi:10.1038/nature10866

van den Bent MJ, Brandes AA, Taphoorn MJ, Kros JM, Kouwenhoven MC, Delattre JY, Bernsen HJ, Frenay M, Tijssen CC, Grisold W, et al. 2013. Adjuvant procarbazine, lomustine, and vincristine chemotherapy in newly diagnosed anaplastic oligodendroglioma: long-term follow-up of EORTC brain tumor group study 26951. J Clin Oncol 31: 344-350. doi:10.1200/JCO.2012.43.2229

Verhaak RG, Hoadley KA, Purdom E, Wang V, Qi Y, Wilkerson MD, Miller CR, Ding L, Golub T, Mesirov JP, et al. 2010. Integrated genomic analysis identifies clinically relevant subtypes of glioblastoma characterized by abnormalities in PDGFRA, IDH1, EGFR, and NF1. Cancer Cell 17: 98-110. doi:10.1016/j.ccr.2009.12.020

Wong AJ, Ruppert JM, Bigner SH, Grzeschik CH, Humphrey PA, Bigner DS, Vogelstein B. 1992. Structural alterations of the epidermal growth factor receptor gene in human gliomas. Proc Natl Acad Sci 89: 29652969. doi:10.1073/pnas.89.7.2965

Wong TN, Miller CA, Jotte MRM, Bagegni N, Baty JD, Schmidt AP, Cashen AF, Duncavage EJ, Helton NM, Fiala $\mathrm{M}$, et al. 2018. Cellular stressors contribute to the expansion of hematopoietic clones of varying leukemic potential. Nat Commun 9: 455. doi:10.1038/s41467-018-02858-0

Wu Z, Huang K, Yu J, Le T, Namihira M, Liu Y, Zhang J, Xue Z, Cheng L, Fan G. 2012. Dnmt3a regulates both proliferation and differentiation of mouse neural stem cells. J Neurosci Res 90: 1883-91. doi:10.1002/jnr .23077

Yamashita Y, Yuan J, Suetake I, Suzuki H, Ishikawa Y, Choi YL, Ueno T, Soda M, Hamada T, Haruta H, et al. 2010. Array-based genomic resequencing of human leukemia. Oncogene 29: 3723-31. doi:10.1038/onc.2010 .117

Yan H, Parsons DW, Jin G, McLendon R, Rasheed BA, Yuan W, Kos I, Batinic-Haberle I, Jones S, Riggins GJ, et al. 2009. IDH1 and IDH2 mutations in gliomas. N Engl J Med 360: 765-773. doi:10.1056/ NEJMoa0808710

Yan XJ, Xu J, Gu ZH, Pan CM, Lu G, Shen Y, Shi JY, Zhu YM, Tang L, Zhang XW, et al. 2011. Exome sequencing identifies somatic mutations of DNA methyltransferase gene DNMT3A in acute monocytic leukemia. Nat Genet 43: 309-315. doi:10.1038/ng.788

Yang Y, Liu R, Qiu R, Zheng Y, Huang W, Hu H, Ji Q, He H, Shang Y, Wang Y. 2013. CRL4B promotes tumorigenesis by coordinating with SUV39H1/HP1/DNMT3A in DNA methylation-based epigenetic silencing. Oncogene 34: 104-118. doi:10.1038/onc.2013.522

Yang L, Rau R, Goodell MA. 2015. DNMT3A in haematological malignancies. Nat Rev Cancer 15: 152-165. doi:10.1038/nrc3895 


\section{COLD SPRING HARBOR Molecular Case Studies}

\section{DNMT3A co-mutation in an IDH1-mutant glioblastoma}

Elena I. Fomchenko, E. Zeynep Erson-Omay, Amy Zhao, et al.

Cold Spring Harb Mol Case Stud 2019, 5: a004119

Access the most recent version at doi: $10.1101 / \mathrm{mcs} . a 004119$

Supplementary http://molecularcasestudies.cshlp.org/content/suppl/2019/07/25/mcs.a004119.D Material C1

References This article cites 47 articles, 9 of which can be accessed free at: http://molecularcasestudies.cshlp.org/content/5/4/a004119.full.html\#ref-list-1

License This article is distributed under the terms of the Creative Commons

Attribution-NonCommercial License, which permits reuse and redistribution, except for commercial purposes, provided that the original author and source are credited.

Email Alerting Receive free email alerts when new articles cite this article - sign up in the box at the Service top right corner of the article or click here. 